\title{
Op soek na gemeentes met integriteit: die bydrae van CW Burger ${ }^{1}$
}

\begin{abstract}
Looking for congregations living with integrity: the contribution of CW Burger

The aim of the article is to reflect on the contribution of dr. Coenie Burger regarding the study of congregations. The focus will be on criteria to identify congregations that are living with integrity. Three aspects need attention in this regard: the identity of a congregation, the direction of a congregation and the fields of ministry of a congregation. Burger uses the notae eccleciae as markers to evaluate the vision, commitment, community and service of a congregation.
\end{abstract}

Gemeentes speel 'n belangrike rol in die kerk en in die gemeenskap. In die kerk word gelowiges saam gegroepeer in geloofsgemeenskappe wat saam aanbid en God dien. Dit is weer lede van die gemeenskap wat saam kom en as gelowiges in die gemeenskap ' $\mathrm{n}$ bepaalde rol speel. $\mathrm{Na}$ beide kante toe kan die kritiese vraag gevra word of gemeentes doen wat hulle veronderstel is om te doen? Is gemeentes nog gelóófsgemeenskappe of het dit maar net nog 'n sosiale instelling geword? Die doel van die artikel is om spesifiek te reflekteer oor die werk van dr. Coenie Burger oor gemeentes en die bediening van gemeentes. Dit is nie moontlik om die volledige veld van gemeentewees, wat deur Burger ondersoek is, te bespreek nie, maar hier sal voorkeur gegee word aan die vraag hoe om geloofwaardige gemeentes na te speur. 'n Kernvraag in die verband is: Wanneer lewe ' $n$ gemeente met integriteit? Watter riglyne kan gebruik word om die stand van gemeentewees te bepaal? Dié vrae sal as raamwerk en fokus gebruik word in die verdere bespreking van Burger se bydrae in die verband.

'n Geloofsgemeenskap kan nie maar net tevrede wees met die normale gang van sake nie, maar behoort gereeld die kritiese vraag vra: Is dit wie en wat ons is, wel die naam kerk en gemeente werd? Dit is'n vraag wat Burger (1999:288) met huiwering vra, en wel om die volgende drie redes:

1. 'n Mens behoort versigtig te wees met jou oordeel oor ander. Die gelykenis van die onkruid (Matt 13:24-30) verduidelik die punt baie goed. Menslike beoordelingsmaatstawwe werk nie altyd goed nie.

2. Die formulering en toepassing van sulke maatstawwe is altyd 'n subjektiewe saak. 'n Eie verstaan is nie noodwendig 'n "regte" verstaan nie.

3. Is die toetsing en evaluering van gemeentewees nie'n te negatiewe proses om 'n positiewe resultaat van te verwag nie? ' $n$ Waardering vir die positiewe kan in die verband 'n konstruktiewe bydrae maak (Schoeman en van den Berg 2011: elektroniese bron).

Die soeke na geloofwaardige gemeentewees dwing 'n mens egter om die vraag na die

1 'n Deel van die artikel was gelewer as 'n voordrag by die kongres: "Theology in times of transition creating a continuous inclusive conversation. A celebration of the work of Coenie Burger." 23 tot 25 Januarie 2012 by Stellenbosch. 
herkenbaarheid van die gemeente te vra. Terme wat soms in die nadenke oor gemeentewees gebruik word is: suksesvol, effektief en relevansie (sien Burger 1999:289, Gaum 2011:93). Dit is terme wat nie kritiekloos op gemeentewees van toepassing gemaak kan word nie. "Dit is nie maklik om vir die kruis en die kruisevangelie plek te maak in 'n suksesvolle kerk nie - ook nie vir die belangrike Bybelse motiewe soos diens, selfverloëning of lyding nie." (Burger 1999:289). Die evaluerende vraag oor gemeentes behoort'n huiwerende maar tog noodsaaklike teologiese vraag te wees. "As ons tog iets wil maak van die reaksie van die mense op die kerk, meen ek dat ons moet vra na die geloofwaardigheid (eie kursivering) van die kerk - eerder as om te flirteer met begrippe soos sukses, gewildheid of erkenning. Die vraag is nie in die eerste plek of mense met ons saamstem of van ons hou of beïndruk is met wat ons doen nie, maar of hulle respek het vir ons integriteit en vir ons eerlike toewyding aan dit waarin ons glo." (Burger 1999:122). Die vraag na die geloofwaardigheid en integriteit van gemeentes is 'n noodsaaklike vraag wat telkens weer en weer gevra moet word. "How is it possible that the gospel should be credible, that people should come to believe that the power which has the last word in human affairs is represented by a man hanging on a cross? I am suggesting that the only answer, the only hermeneutic of the gospel, is a congregation of men and women who believe it and live by it

..." (Newbegin 1989:227). In navolging van, onder andere Newbegin, vra Burger die vraag na die integriteit van geloofsgemeenskappe.

As dit gaan oor meer as die sukses en effektiwiteit van 'n gemeente, hoe kan 'n gemeente beskryf word om die integriteitsvraag te antwoord? As beginpunt word gekies om te kyk na die aard van 'n gemeente. In terme van watter konsepte en riglyne kan 'n gemeente beskryf word? Op voetspoor van Burger kan drie vrae in die verband gevra word:

- Aan wie behoort 'n gemeente;

- wat behoort'n gemeente te doen

- en hoe word'n gemeente se bediening beskryf?

In die beantwoording van die drie vrae sal daar veral gekyk word na die bydrae van Burger (1991, 1995, 1997, 1999, 2001, 2002 en 2008) en ook hoe dit kan help om die geloofwaardigheid en integriteit van'n gemeente te karteer.

\section{DIE IDENTITEIT VAN'n GEMEENTE -'n WESENLIKE VRAAG}

Die wesentlike vraag is: aan wie behoort 'n gemeente? Gemeentes se identiteit lê in hulle verhouding met God: hulle behoort aan God. God Drie-enig het ' $n$ verbond met elke gelowige, en daarom ook met die gemeente, gesluit. Die vraag na die identiteit van die gemeente is'n vraag na die wese of die oorsprong van die gemeente. Dit beteken dat die oorsprong van die gemeente alleen in die gemeente se verhouding met die drie-enige God gevind kan word. "Die kerk kan sonder die Gees, die Seun en die Vader nie bestaan nie en nog minder verstaan word. Dit is die eerste en ook wortelverhouding waarin die kerk staan." (Heyns 1977:85). Van Gelder (2000:35) en Guder (2000:28 e.v.) beklemtoon verder die Triniteit as vertrekpunt vir die verstaan van die identiteit van die kerk en gemeente.

Burger (1999:55-63 en 2001:15-18) trek 'n paar duidelike riglyne oor die identiteit van gemeentes. Die gemeente se verhouding met die Here is ' $n$ baie eksklusiewe verhouding. Die Eerste Gebod wys daarop dat 'n gemeente nie twee Here mag dien nie, maar alleen aan die lewende God verbind moet wees. Die Here het die reg op hierdie eksklusiewe verhouding met sy volk omdat Hy hulle gered het. Die inisiatief lê by God en daarom word sondaars as sy kinders aangeneem. Dit lei tot gemeenskap tussen God en sy gemeente. Die Here se reg op die volk word 
gekwalifiseer deur die feit dat Hy hulle liefhet en dat Hy wil hê hulle moet Hom liefhê. Metafore wat in hierdie verband gebruik word, is: ouer-kind, nuwe familie en huisgesin (sien ook Burger 1997:125-165). Die Here Jesus het sy dissipels lief en verwag dat hulle Hom in gehoorsaamheid sal volg. Die gemeente bewys hulle liefde vir die Here deur sy wil te doen en sigbaar aan Hom gehoorsaam te wees. Die liefdesgebod, die Wet van God en liefde wat sigbaar word, bevestig 'n geloofsverhouding met Jesus Christus. "Identiteit waarvan niks sigbaar word nie, is min werd." (Burger 1999:61). Die gemeente word opgeroep om met God te leef, soos wat Hy Hom aan hulle bekendmaak. Die Tweede Gebod vra dit ondermeer van 'n gemeente.

Die vraag na die identiteit van die gemeente plaas baie direk die integriteit van die gemeente op die tafel. Die vraag na die gemeente se identiteit vra na die belydenis en die geskiedenis of verhaal van die gemeente. Dit is in die eerste plek ' $n$ konfessionele identiteit: Vir die meeste gemeentes is hulle konfessionele agtergrond deel van hulle identiteit (Burger 1999:70). Dit bring byvoorbeeld die gemeente se verstaan van 'n gereformeerde identiteit na vore.

Tweedens vra die identiteitsvraag na die verhaal van die gemeente, drie faktore het ' $n$ sterk vormende invloed op die narratiewe aard van die gemeente:

- die ontstaansgeskiedenis van 'n gemeente (bv. die aanleidende faktore vir die stigting van die spesifieke gemeente);

- die pioniersleiers wat'n sentrale rol gespeel het by die stigting van die gemeente (predikante, kerkraaslede ens);

- belangrike gebeurtenisse in die ontplooiing van die gemeente se verhaal (Burger 1999:71).

'n Ondersoek na die gemeente se konfessionele en historiese identiteit lê die antwoorde oor die vraag aan Wie die gemeente behoort, bloot. Gemeentes se identiteit is daarom grondig anders as die van byvoorbeeld'n sosiale vereniging. Die werk van Burger kan in die verband deur 'n narratiewe aanpak 'n treë verder geneem word. In die soeke na die gemeente se identiteit behoort die verhale in en oor die gemeente opgeteken en geanaliseer te word. Op'n narratiewe en kwalitatiewe vlak kan die verhale van gemeentes veel oor die konfessionele identiteit van ' $n$ gemeente sê. 'n Spesifieke narratiewe metodologie kan hiervoor ontwikkel word.

\section{DIE BESTAANSDOEL VAN 'n GEMEENTE -’n RIGTINGGEWENDE VRAAG.}

In watter rigting of koers behoort'n gemeente te beweeg? Die identiteit van die gemeente dien as vertrekpunt vir die bepaling van die doel van die gemeente. Wat'n gemeente behoort te doen word direk gekoppel aan die identiteit van die gemeente. Uit die identiteit van die gemeente kom die bestaansdoel van die gemeente na vore. Die missie dui die doel van die kerk aan (Burger 1999:77). Ander terme wat in dié verband vir die doel van die gemeente gebruik kan word, is: roeping, opdrag, gestuurdheid of sending van die gemeente.

Die vroeë christelike kerk het 'n sterk missionêre ingesteldheid gehad. Die sending van die vroeë kerk het gedraai om die besef dat God se Koninkryk in Jesus Christus'n werklikheid geword het. Bosch (1991:54) vat die missionêre ingesteldheid van die vroeë geloofsgemeenskap soos volg saam: "The New Testament witnesses assume the possibility of a community of people who, in the face of the tribulations they encounter, keep their eyes steadfastly on the reign of God by praying for its coming, by being its disciples, by proclaiming its presence, by working for peace and justice in the midst of hatred and oppression, and by looking and working toward God's liberating future." Die vroeë gemeentes het 'n duidelike verstaan van hulle opdrag en roeping gehad.

Hoe sou die taak of doel van'n gemeente beskryf kon word? Burger (1999:79-84) wys op die 
volgende riglyne waarlangs dit beskryf sou kon word:

- Die kerk is'n gemeenskap met'n opdrag. Die kerk is eiendom van God en daarom in sy diens. Metafore om die opdrag mee te benoem is onder andere: sout van die aarde, dienskneg, boodskapper of ambassadeur.

- Die inhoud van die opdrag is om getuies in diens van Jesus Christus en sy Evangelie te wees. Die kerk het die opdrag om Jesus Christus as Here te verkondig.

- Die inhoud van die Evangelie is veelkantig en inklusief. Die heil en verlossing wat Jesus bring, is omvattend, daarom is dit nodig om wyd en inklusief oor die verlossing wat Jesus gebring het, te dink.

'n Gemeente voer sy opdrag uit deur getrou aan sy identiteit te wees. Die gemeentedoel is nie onderhandelbaar nie, aangesien dit deel van die wese van'n gemeente is. Die volgende aspekte kan as wesenlik deel van die gemeentedoel uitgewys word (vergelyk Burger 1999:84-90):

- Die doel van Christus se missie en gevolglik die gemeente se doel, is ' $n$ heelgemaakte wêreld, 'n wêreld wat met God versoen is. Die Koninkryk is groter as die kerk. Die kerk en gemeente staan op alle lewensterreine in diens van die koms van die Koninkryk.

- Die gemeente is teken en getuienis van die heil: getuies nie net in wat die gemeente sê en doen nie, maar ook in wat die gemeente is - "sout vir die aarde" en "lig vir die wêreld". Die geloofsgemeenskap stel daarom 'n voorbeeld aan die gemeenskap. "'n Sterk missionêre bediening sonder ' $n$ duidelik evangeliese lewenstyl en identiteit gaan op die lange duur geen geloofwaardigheid hê nie. Ons moet aan die een werk, sonder om die ander na te laat." (Burger 1999:88). Gemeenskap deurbreek die eensaamheid en vervreemding in intermenslike verhoudinge. Die gemeente is getuie dat Christus mure afbreek.

- Dissipels (en burgers) is getuies op die markplein. Dit is ' $n$ getuienis van liefde en geregtigheid teenoor groepe, gemeenskappe, instansies en samelewingstrukture; juis ook op die markplein en nie net tydens die gemeente se amptelike byeenkomste nie. "Bevordering van recht en gerechtigheid jegens allen die lijden onder onderdrukkende en onrechtvaardige situasies, de slachtoffers van radicale, politieke en economische onderdrukking, discriminatie en vervolging" (Noordegraaf 1998:193).

In 'n latere artikel (2008) wys Burger pertinent op die publieke rol van die geloofsgemeenskap. Die kerk en veral gemeentes het 'n bepaalde rol om binne die breër samelewing te speel. Die publieke kerk is nie net oor sy eie lidmate besorg nie, maar speel ook in die samelewing 'n belangrike rol, omdat God drie-enig die Verlosser vir die hele wêreld is (Burger 2008:249). Gemeentes het 'n baie duidelike publieke rol en dit is gekoppel aan die doel of missionêre verstaan van die gemeente. Sou gemeentes dit vandag nog so verstaan of bring die gerigtheid op "eie" lidmate die integriteit van gemeentes onder verdenking?

In 'n wêreld wat deur ' $n$ post-christendom leefstyl gekenmerk word het die sendingveld weer die grense en bestaanswêreld van die gemeente op 'n unieke wyse binnegekom. "A very uncertain congregation, then, looks across an unfamiliar missionary frontier to an environment that appears less and less friendly and wonders." (Mead 1991:27). Die verskuiwing beteken dat gemeentes weer opnuut sal moet analiseer hoe om die missio Dei vandag uit te leef.

Indien 'n gemeente sy gerigtheid op sy bestaansdoel verloor, verloor die gemeente sy greep op sy bestaansrede. Die wesenlike gevaar bestaan dat 'n gemeente baie goed kan funksioneer, baie aksies en aktiwiteite kan onderneem, maar sy doel uit die oog kan verloor. Gemeentes fokus dan meesal op instandhouding van die status quo. As dit gebeur is'n gemeente niks meer 
as'n goeie en effektiewe organisasie of sosiale instelling nie. Dit is daarom noodsaaklik om in die vraag na die integriteit van die gemeente altyd die bestaansdoel van'n gemeente voor oë te hou. 'n Kritiese analise en selfondersoek is daarom noodsaaklik.

\section{GEMEENTELIKE BEDIENING - OP WATTER TERREINE?}

As die missio Dei die missio ekklesia bepaal, is die volgende noodwendige vraag: Op watter verskillende terreine vind die gemeentelike bediening plaas, sodat die gemeentedoel bereik kan word? Die konsep "bedieningsterrein" gee'n omvattender beskrywing van wat as die "funksies" van die kerk verstaan kan word (sien Pieterse 1991:67-68). Burger definieer bediening soos volg: "Ons bedoel met bediening van die kerk die totaliteit van aktiwiteite waardeur die kerk of gemeentes probeer uitvoering gee aan hulle missie." (1999:104). Die bediening van die Evangelie geskied deur die werksaamheid van die Heilige Gees; dit is ' $n$ omvattende opdrag. In die uitvoering hiervan gebruik die Gees mense en ander middele. Die getuienis van die totale gemeente is so 'n middel wat die Gees gebruik. Die gemeente word gesien as die eerste en primêre middel wat die Gees in sy werk met betrekking tot die kommunikasie van die Evangelie wil gebruik (Burger 1999:104). Dit wat die gemeente is, sê (of bely), doen en bid, moet in kongruensie wees vir die gemeente om geloofwaardig te wees. Gemeentelike aktiwiteite kan op 'n verskeidenheid van bedieningsterreine geskied.

Burger kies die volgende vier bedieningsterreine vir'n gemeente as terreine waarbinne die totaliteit van gemeentelike aktiwiteite behoort te val om uitvoering aan die gemeente se missie of bestaansrede te gee (sien ook die bydrae van Louw 1992:130-131, Pieterse 1993:160-161 en Nel 1994:27 oor die vier bedieningsterreine):

- Leitourgia: “Die term word hier gebruik as'n koepelbegrip vir al die aanbiddingsaktiwiteite van die gemeente." (Burger 1999:204). Die klassieke en mees algemene vorm van leitourgia vind in die erediens plaas. Liturgie beteken om te bid.

- Kerugma verwys na die verkondiging of bekendmaking van die boodskap van die evangelie. "Kerugmatiese diens, soos dit hier verstaan word, verwys na alle aktiwiteite in die gemeente wat primêr gefokus is op die Bybel en sy unieke boodskap - hetsy dit is om die boodskap beter te hoor, dit te verstaan, dit met ander te bespreek of om dit deur te gee aan mense wat dit nog nie ken nie." (Burger 1999:216). Dit vind in die erediens plaas, maar ook baie wyer in die gemeentelike aktiwiteite.

- Koinonia: "Dit gaan oor die ondersteunende en gemeenskaplike aktiwiteite wat gelowiges in die gemeente uitvoer waardeur Christene aanmekaar gebind word en so die versorgende en helende krag van die evangelie ervaar." (Burger 1999:231). Koinonia staan in'n noue verband met die gemeente se missie tot liefde. lets van die Bybelse shalom - gemeenskap moet weerspieël word. Die samekomste van die gelowiges speel in die verband' $n$ belangrike rol. In die Ou Testament word die geloofsgemeenskap deur die Tora saamgebind. In die Nuwe Testament gee Jesus aan sy dissipels die opdrag om mekaar lief te hê sodat die wêreld iets van Hom en sy liefde in hulle lewe sal sien (Joh. 13:35, Joh. 17:20-26).

- Diakonia wys daarop dat gelowiges God sal eer ".... deurdat ons ander mense en sy skepping dien met selfverloënende dade van liefdesdiens." (Burger 1999:245). Daar bestaan'n sterk band tussen geregtigheid en diens. Diakonia beteken dat gelowiges bereid sal wees om te doen wat reg is (Miga 6:8, Matt 7:23). "Dit is waarskynlik die bediening wat deur die eeue die meeste afgeskeep is deur die kerk" (Burger 1999:246). 
Hierdie gemeentelike bediening moet nie as' $n$ versmalde bediening van net die ampte verstaan word nie, maar as 'n omvattende bediening van die totale gemeente (Burger 1999:108-109). Dit is meer as net die werk van ampsdraers en kommissies in gemeentes. Gemeente en lidmate is omvattend by al die bedieninge betrokke.

Burger (1999:112) maak'n onderskeid tussen die opbou na binne en die uitreik na buite ten opsigte van elk van die vier terreine. Die onderskeid tussen opbou na binne en uitreik na buite is, in die lig van die bestaansdoel van die gemeente, problematies. In 'n later werk (2002:267273) laat vaar Burger die onderskeid tussen na binne en na buite. Dit is 'n verbetering, want dit laat groter reg geskied aan die missionêre doel van 'n gemeente. Alle gemeentelike bediening geskied vanuit die gemeente se missionêre opdrag en nie vanuit 'n onderskeid tussen "binne" en "buite" nie.

Die vraag na die stand en integriteit van die gemeente is ' $n$ vraag na' $n$ balans tussen die vier bedieningsterreine. Die gevaar bestaan dat een of meer van die terreine afgeskeep kan word. Sonder om die belang van die erediens te onderskat, vind daar ook liturgiese- en kerugmatiese handelinge in 'n kleingroep plaas of het'n erediens ook'n sterk diakonale en koinoniale dimensie. 'n Verdere vraag is ook wat gebeur op die vier terreine van Maandag tot Saterdag in die lewe van die geloofsgemeenskap? Die vier praktyke is verder deel van die publieke getuienis en lewe van die gemeente (Burger 2008:253). Is daar op al vier terreine'n openheid en interaksie tussen gemeente en gemeenskap? Die belangrike en kritiese vraag plaas die gemeente vierkantig binne die publieke lewe.

\section{4. ’n TEORIE OM DIE GEMEENTE SE FUNKSIONERING MEE TE ONDERSOEK.}

Burger se boek Die dinamika van 'n Christelike geloofsgemeenskap verskyn in 1991 en word met die Andrew Murray prys bekroon. Die bedoeling van die boek was om 'n teorie oor die funksionering van 'n geloofsgemeenskap vir oorweging op die tafel te sit (Burger 1991:149). Burger (1991:20-21) onderskei vier prosesse wat in die dinamika en funksionering van 'n gemeente aan die werk is:

- Visie: van statiese formules tot 'n hoopvolle visie

- Verbintenis: van vae instemmings tot'n vaste verbintenis

- Gemeenskap: van privatisme en selfsorg tot sorg vir mekaar

- Diens: van 'n selfgerigte verstandsgodsdiens tot'n lewe van daadwerklike diens.

Sou hierdie vier prosesse gebruik kon word om 'n gemeente se integriteit mee te analiseer? Burger verskaf self die antwoord deur ten opsigte van elkeen van die prosesse ' $n$ teologiese kontrolepunt van uit die eienskappe van die kerk te identifiseer. Die vier eienskappe dien in 'n meerdere of mindere mate by elkeen as kontrolepunt, maar daar is in elke geval minstens ' $n$ primêre punt wat Burger uitlig. In'n latere werk brei Burger verder uit op die vier eienskappe van die kerk as'n manier om die gehoorsaamheid en outentiekheid van'n gemeente te toets (Burger 1999:290-299).

In die Geloofsbelydenis van Nicea en die Apostoliese Geloofsbelydenis word vier eienskappe van die kerk bely: sy eenheid, heiligheid, algemeenheid en apostolisiteit. "Die eienskappe is deur God aan die kerk as gawe geskenk om daardeur die wyse van die kerk se bestaan in die wêreld aan te dui; die eienskappe is egter ook as opdrag deur God aan die kerk gegee om daardeur die taak van die kerk in die wêreld aan te dui; en die eienskappe is ook as belofte deur God aan die kerk gegee om daardeur die kerk steeds op die volheid in die toekoms gerig te bly hou." (Heyns 1981:377). Heitink (2007:28-32) gebruik ook die vier eienskappe as'n vertrekpunt vir die 
ontwikkeling van 'n ekklesiologie (sien ook Breytenbach en Pieterse 1992:102 en Dreyer 2009: elektroniese bron in die verband).

Burger soek die antwoord na 'n beter toets vir die gemeente se gehoorsaamheid, wat ook rekening hou met die unieke aard van gemeentewees, deur die vier eienskappe van die kerk te gebruik. Die vier prosesse met hulle primêre kontrolepunte word vervolgens bespreek:

Eerstens gaan dit oor'n gedeelde visie op die koninkryk van God. "Sonder'n visie wat funksioneer op die vlak van 'n gedeelde droom kan daar nie sprake wees van 'n lewende en effektiewe geloofsgemeenskap nie."(Burger 1991:37). Die primêre kontrolepunt ten opsigte van die visie van die geloofsgemeenskap is die Christelikheid of apostolisiteit van die kerk. Die waarheid van die evangelie word op die punt gekontroleer. Die vraag is: "Is dit werklik in sy wese 'n Christelike visie op die wêreld?" (Burger 1991:67). Dit gaan oor die navolging van die leer van die apostels (Heitink 2007:31). Die Skrif dien as die finale maatstaf en bron van waarheid vir die kerk. Die Woord word daarom deur die gemeente ernstig opgeneem en as riglyn vir die gemeentelike lewe aanvaar. Dit sou dit insluit dat die kerklike tradisie ook ernstig opgeneem word. Die vraag oor die geloofwaardigheid van die gemeente is na die erns waarmee die apostolisiteit van die gemeente opgeneem word, word genoeg van die gemeente se energie aan die apostolisiteit van die kerk gespandeer? (Burger 1999:299).

Tweedens behoort daar ' $n$ vaste geloofsverbintenis aan die visie te wees. ' $n$ Lewende en effektief funksionerende geloofsgemeenskap is afhanklik van die lede se vaste, kontroleerbare geloofsverbintenis aan die visie van die gemeente (Burger 1991:73). Die heiligheid van die kerk is in die verband die primêre kontrolepunt van die geloofsverbintenis. Word die geloofsgemeenskap herken as mense wat aan Christus behoort en so lewe? (Burger 1991:94). Dit gaan oor die gemeente se toewyding aan die taak van die kerk, oor die andersheid van gesindheid en lewe wat die evangelie van lidmaat en gemeente vra. ' $n$ Lewe van liefde, ' $n$ lewe wat kies vir wat reg is en wat op alle lewensterreine na vore kom is hier ter sprake. In die soeke na integriteit word gevra na die konsekwensies van so 'n lewe vir die gemeente se waardes en prioriteite. Is daar ' $n$ entoesiasme en vreugde vir so ' $n$ lewenswyse van heiligheid (Burger 1999:295)? Alfsvåg (2008:37) wys daarop dat die tien gebooie en ook die uitleef van geloof, hoop en liefde merkers sou kon wees van so'n gehoorsame lewe.

Derdens is daar in die gemeente'n sorgende gemeenskapslewe (koinonia) waarin mense mekaar op hierdie pad ondersteun. "Gemeenskap" verwys na 'n diep lewens- en lotsverbondenheid wat die Christelike geloofsgemeenskap kenmerk (Burger 1991:99). Is daar ruimte en plek vir elkeen binne in die geloofsgemeenskap, daarom is die eienskap van katolisiteit die primêre kontrolepunt in die verband (Burger 1991:116). Werklike koinonia word eers getoets as by dit "andersdenkendes" kom. Die katolisiteit van die kerk beteken dat dissipelskap alle ander verhoudinge te bowe gaan. Alle gelowiges deel die belydenis met mekaar. Dit behels'n openheid teenoor alle lewe en alles wat God geskep het. Die konsekwensie van die eienskap is dat alle Christene in die gemeente welkom is en met vrymoedigheid ontvang moet word. Die katolisiteit van die kerk vra of 'n gemeente 'n oop deur en hart het vir alle gelowiges, ook die wat anders is en anders dink as waaraan die gemeente normaalweg gewoond is (Burger 1999:298). Heitink (2007:30-31) wys op 'n kwantitatiewe en kwalitatiewe aspek in die verband, aan die een kant omvat dit 'n deel van die mense, maar aan die anderkant is dit vir alle mense. Die sorgende gemeenskap is oop vir alle mense.

Vierdens plaas die gemeente klem op'n sterk georiënteerdheid op dade en doen, in die wete dat 
die kern van die christelike lewe diens is. Geloof word sigbaar deur selfverloënende dade van diens en liefde aan God, die naaste en hele wêreld. Die kerk is 'n diensgemeenskap en bestaan nie ter wille van homself nie (Burger 1991:123). Diens gaan oor 'n getuienis teenoor die hele wêreld. Indien die eenheid 'n realiteit binne die lewe van die geloofsgemeenskap is, sal die mense begin om mekaar te dien in die gesindheid en liefde van Christus. Die eenheid van die kerk funksioneer daarom as primêre kontrolepunt in die verband (Burger 1991:143). Eenheid en liefde hang ten nouste saam met, en is'n bevestiging van die gemeente se identiteit in Jesus Christus. Die herkenbaarheid van die eenheid van die kerk op gemeentevlak kan aan die hand van die volgende getoets word (Burger 1999:293): Verstaan die gemeente dat die egtheid van die gemeente se identiteit in Christus getoets word aan die hand van die gelowiges se uitleef van liefde en eenheid met ander gelowiges? Verstaan die gemeente die radikaliteit hiervan en hoe dit verhoudings beïnvloed? Kerklike verdeeldheid is daarom pynlik en onaanvaarbaar (Heitink 2007:30).

Die akuutste probleem vir die NG Kerk in 1991 is op die vlak van die kwaliteit van lidmate se geloofsverbintenis (Burger 1991:151). Die sigbaarheid van 'n heilige lewe is onder verdenking. Hoe sou dit aangespreek kon word? Burger stel voor dat daar begin word by die derde beginsel - 'n lewende onderlinge gemeenskap (koinonia). Direk daarmee saam word aandag gegee aan diens en dan visie voordat by die geloofsverbintenis uitgekom word. Hoe sou dit in 2012 beskryf kon word? Die grootste uitdaging vir gemeentes is waarskynlik op die vlak van diensbaarheid aan die gemeenskap en daarmee saam die gebrek aan eenheid as kontrole punt. Die gemeentelewe is op selfsorg gerig met ' $n$ sterk klem op 'n geprivatiseerde godsdienstige lewe (Sien Schoeman 2010:123). Die uitdaging vir gemeentes lê in 2012 op die vlak van gesamentlike diens in die gemeenskap.

\section{5. 'n VERDERE TREE OPSOEK NA GEMEENTES MET INTEGRITEIT}

Burger en Heitink, soos hierbo aangetoon, gebruik die eienskappe van die kerk as indikatore om die integriteit van die gemeente mee te ondersoek. Dit help beslis, maar is die gebruik van die eienskappe genoegsaam of sou'n verdere tree gegee kon word? Die kenmerke van die kerk sou in die verband kon help (sien ook Gaum 2011:75-76). Die kenmerke van die kerk, gesien vanuit die Reformasie-oogpunt, is voorwaardes vir kerk-wees. Die Reformasie het daarop gewys dat die kerk uitwendig aan die eienskappe kan beantwoord - formeel altans - en tog nie die ware kerk is nie. Die empiriese kerk is nie vanselfsprekend die ware kerk nie en daarom het die reformatore 'n kritiese maatstaf ingevoer wat as die kenmerke bekendstaan. Die kenmerke van die kerk word gebruik om tussen die ware en die valse kerk te onderskei (Jonker 1994:75). Die Reformasie dui as kenmerke van die ware kerk die suiwere en by name die amptelike bediening van die Woord, die sakramente en die tug aan (NGB Art. 29).

Die kerk is nie in sy suiwer gestalte in die wêreld te vinde nie. Juis daarom is dit die taak van die kerk om voortdurend in die lig van die eise van die Woord te reformeer. "Eintlik het die ware kerk maar een kenmerk, en dit is of die Woord daarin heers, terwyl die vals kerk die Woord op allerlei maniere minag en aan homself en sy eie besluite meer gesag toeskryf." (Jonker 1994:75). Dit is vir gemeentewees belangrik, aangesien dit beteken dat 'n gemeente altyd selfondersoekend besig moet wees om toenemend in gehoorsaamheid aan die Woord te lewe. 'n Gemeente binne die reformatoriese tradisie sal altyd hierdie kenmerke as deel van sy belydenisgrondslag moet verreken. Dit help gemeentes om met groter integriteit as gemeente binne en vanuit die reformatoriese belydenis te lewe.

Die kenmerke is voorwaarde vir die kerk, daarom is dit ook voorwaarde vir die eienskappe van 
die kerk. Indien aan die bepaalde voorwaardes voldoen word, ontstaan'n kerk en gemeente met bepaalde eienskappe. As daar dus analities na'n gemeente gekyk word, moet die kenmerke van die kerk, vanuit hierdie belydenis, ook ten opsigte van die spesifieke gemeente, verreken word. Binne 'n gemeente konteks kom vrae na die gehoorsaamheid aan die Woord, die gebruik en viering van die sakramente en die uitlewe van 'n daadwerklike liefdesgemeenskap aan die orde. Die kenmerke kan, naas die vier eienskappe, as'n verdere stap gebruik word as rigtingwysers in die soeke na'n gemeente met integriteit.

\section{MERKERS VIR'n GEMEENTE MET INTEGRITEIT}

Sonder om die rol van strukture, strategieë en selfs leierskap in die gemeente te onderskat (sien Burger 1995:38 oor die kongruensie tussen die komponente), is 'n teologiese verstaan van wat dit beteken om 'n geloofwaardige geloofsgemeenskap te wees noodsaaklik. Burger het hiermee beslis gehelp deur vrae na die identiteit, taak en bedieningsterreine van die gemeente op die tafel te plaas. 'n Grondige teologiese verstaan van wat dit beteken om 'n geloofwaardige gemeente of ' $n$ gemeente met integriteit te wees is daarom nodig. Dit is wesenlike en rigtinggewende vrae wat herhaaldelik beantwoord moet word.

'n Verdere stap in die soeke na geloofwaardigheid, wat Burger ook uitgewys het, is die gebruikmaking van die eienskappe van die kerk. Barth maak die volgende insiggewende opmerking oor die rol van die belydenis van die vier eienskappe in die gemeente: "Credo ecclesiam means that I believe that the congregation to which I belong, in which I have been called to faith and am responsible for my faith, in which I have my service, is the one, holy, universal Church. If I do not believe this here, I do not believe it at all." (1949:144). Die belydenis van die eienskappe en ook die kenmerke van die kerk, kan gemeentes help om met integriteit te lewe.

\section{BIBLIOGRAFIE}

Alfsvåg K 2008. Notae ecclesiae in Luther's Von den Konziliis und Kirchen International Journal for the Study of the Christian Church. Vol. 8, No. 1, February 2008, 33-42

Barth K. 1949. Dogmatics in outline. Londen: SCM Press Ltd,.

Bosch D.J. 1991. Transforming mission. Paradigm shifts in Theology of Mission. New York: Orbis Books. Dreyer, T.F.J., 2009, “n Kerk met karakter: Die perspektief van Gerben Heitink', HTS Teologiese Studies/

Theological Studies 65(1), Art. \#315, 5 bladsye. DOI: 10.4102/hts.v65i.315

Breytenbach, H.S. EN Pieterse, H.J.C. 1992. Doelwitte vir gemeentebou in die lig van ' $n$ prakties-teologiese ekklesiologie. PTSA, no 7(2): 101-112.

Burger, C.W., 1991, Die dinamika van 'n Christelike geloofsgemeenskap Kaapstad:Lux Verbi.

Burger, C.W., 1995, Gemeentes in transito. Vernuwingsgeleenthede in 'n oorgangstyd. Kaapstad:Lux Verbi.

Burger, C.W., 1997, Familie van God! 'n Ander manier van dink oor God, oor geloof en oor die kerk.

Kaapstad:Lux Verbi.

Burger, C.W., 1999, Gemeentes in die Kragveld van die Gees. Bloemfontein: CLF-Drukkers.

Burger, C.W., 2001, Ons weet aan wie ons behoort. Nuut gedink oor ons gereformeerde tradisie.

Wellington:Lux Verbi.

Burger C. en Nell I (redakteurs), 2002. Draers van die waarheid: Nuwe Testamentiese visies vir die gemeente. Matieland: BUVTON.

Burger C.W. 2008. Die reformatoriese verstaan van die geloofgemeenskap (gemeente) as ' $n$ publieke gemeenskap. Scriptura no 99: 247-258.

Gaum F 2011. Fluit-fluit die kerk is uit? Wellington: Bybel-Media.

Guder, D.L. 2000. The continuing conversion of the church. Grand Rapids, Michigan: William B. Eerdmans Publishing Company,

Heitink G 2007. Een kerk met karkater. Tijd voor herorientatie. Kampen: Uitgeverij Kok. 
Heyns J.A. 1977. Die Kerk. Pretoria: N.G. Kerkboekhandel.

Heyns J.A. 1981. Dogmatiek. Pretoria: N.G. Kerkboekhandel, 2 de druk.

Jonker W.D. 1994. Bevrydende Waarheid. Wellington: Hugenote Uitgewers.

Louw D.J. 1992. Die ontwerp van 'n prakties-teologiese ekklesiologie vir gemeentebou, PTSA, 7(2).

Mead L.B. 1991. The once and future church. New York: Alban Institute.

Nel, M. 1994. Gemeentebou. Halfway House: Orion Uitgewers.

Newbigin. L. 1998. The Gospel in a pluralist society. Grand Rapids: William B. Eerdmans Publishing Company.

Noordegraaf A. 1998. Vijf broden en twee vissen. Zoetemeer: Uigeverij Boekencentrum.

Schoeman, W.J. 2010. The Congregational Life Survey in the Dutch Reformed Church: Identifying strong and weak connections. Ned Geref Teologiese Tydskrif. 51(3-4): 114-124

Schoeman, K. \& Van den Berg, J.A. 2011. An appreciation for the positive! Appreciative engagement as congregational- and pastoral lens. Hervormde Theological Studies: 76(2): Art. \#887, 7 bladsye. DOI:10.4102/hts.v67i2.887.

Van Gelder C. 2000. The essence of the church. A community created by the Spirit. Grand Rapids: Baker Books.

\section{KEY WORDS}

congregations

Coenie Burger

notae ecclesiae

ministry

\section{TREFWOORDE}

gemeentes

Coenie Burger

notae ecclesiae

bediening

Kontakbesonderhede:

Prof. W.J Schoeman

Departement Praktiese Teologie

Fakulteit Teologie

Universiteit van die Vrystaat

E-pos: schoemanw@ufs.ac.za 